“Transfer” XV: 1-2 (2020), pp. 115-141. ISSN: 1886-554

\title{
"UN ESPACIO DE TRABAJO EN RELACIÓN": EL ENSAYO FEMINISTA TRADUCIDO DE LASAL, EDICIONS DE LES DONES
}

Pilar Godayol (ORCID: 0000-0003-2513-5334)

Universitat de Vic - Universitat Central de Catalunya

\section{Introducción: tres décadas de género, mujer y traducción}

En los últimos treinta años la historia, la teoría y la práctica de la traducción desde una perspectiva de género han propiciado una investigación fecunda y variada a nivel nacional e internacional. Aunque la díada "mujer" y "traducción" ya existía desde hace siglos en la literatura universal, fue en los años ochenta, en Quebec, donde empezó a ser reivindicada. Diferentes coordenadas sociales, políticas e identitarias confluyeron (el feminismo anglo-sajón, el feminismo francés, el "cultural turn" en los estudios de traducción, el posestructuralismo, el deconstruccionismo, etc.) y empujaron a algunas escritoras y traductoras feministas a subvertir y manipular con su escritura o (re)escritura el discurso dominante androcentrista (Nicole Brossard, Luise von Flotow, Barbara Godard, Susanne de Lotbinière-Harwood, Sherry Simon, etc.). Paralelamente, en Estados Unidos, otras autoras también teorizaban sobre la práctica de la traducción literaria feminista (Lori Chamberlain, Myriam Díaz-Diocaretz, Suzanne Jill Levine, Carol Maier, Gayatri Ch. Spivak, etc.).

A finales de los años noventa se inauguraron nuevas iniciativas fuera del continente norteamericano. El Estado español fue uno de los primeros países en el cual diferentes investigadoras se centraron en este objeto de estudio. Por ejemplo, en 1998, la pionera África Vidal Claramonte, le dedicaba un capítulo, "Teorías feministas de la traducción”, en el libro El futuro de la traducción, y Pilar Godayol leía la primera tesis sobre género y traducción (Espais de frontera. Gènere i traducció, 2000 [Spazi di frontiera. 
“Transfer” XV: 1-2 (2020), pp. 115-141. ISSN: 1886-554

Genere e traduzione, 2002]). Con el cambio de milenio, los estudios se expandieron a otros territorios europeos y se introdujeron en otros continentes, $y$, en nuestra geografía, proliferaron los congresos, las publicaciones y las tesis. En este sentido, y como ejemplos recientes de la frenética actividad de los últimos dos años de las autoras ibéricas, destacamos las siguientes monografías: Translation, Ideology and Gender (2017), editado por Carmen Camus, Cristina Gómez Castro y Julia Williams Camus; Feminist Translation Studies. Local and Transnational Perspectives (2017), editado por Olga Castro y Emek Ergun; Tres escriptores censurades. Simone de Beauvoir, Betty Friedan \& Mary McCarthy (2016) [Tres escritoras censuradas. Simone de Beauvoir, Betty Friedan y Mary McCarthy (2017)], de Pilar Godayol; Traducir para la igualdad sexual (2017), editado por José Santaemilia; Foreign Women Authors under Fascism and Francoism: Gender, Translation and Censorship (2018), editado por Pilar Godayol y Annarita Taronna, y Traducción, género y censura en la literatura y en los medios de comunicación (2018), editado por Gora Zaragoza, Juan José Martínez Sierra, Beatriz Cerezo y Mabel Richart.

En resumen, en los últimos veinte años el estudio de la intersección "género, mujer y traducción" ha propiciado en las universidades españolas, entre otros logros: a) la recuperación de traductoras, textos y paratextos, invisibilizados por los discursos dominantes; b) la interrogación, la crítica y la autocrítica de las teorías y las prácticas de la traducción feministas de aquí y de fuera; c) la reflexión sobre la ética y la responsabilidad de las traductoras feministas y las editoriales que publican sus textos; d) el estudio de la representación lingüística del género en traducción; e) el análisis lingüístico de las traducciones feministas y de las sexistas; e) la promoción de metáforas y mitos en femenino para substituir el discurso traductológico androcentrista tantos años vigente en las teorías de la traducción; etc. Obviamente, como en toda disciplina abierta a los cambios intelectuales y tecnológicos del tercer milenio, quedan desafíos importantes que atender, como, por ejemplo, acortar distancias entre la teoría y la 
“Transfer” XV: 1-2 (2020), pp. 115-141. ISSN: 1886-554

práctica o la academia y la traducción profesional, así como la academia anglo-americana y europea y la academia en otras geografías.

En el contexto catalán, una de las líneas de investigación más fructíferas ha sido la colaboración y retroalimentación entre la historia de la traducción y la historia de las mujeres. El grupo de investigación GETLIHC (Grupo de Estudios de Género: Traducción, Literatura, Historia y Comunicación), de la Universidad de Vic, en colaboración con el GETCC (Grupo de la Traducción Catalana Contemporánea), de la Universidad Autónoma de Barcelona, ha investigado en esta línea. Muchos de sus trabajos se han centrado en la visibilización de traductoras, sus paratextos y las condiciones sociales, políticas y culturales de su producción. En definitiva, cabe destacar que, con otras iniciativas como las del grupo BITRAGA de la Universidad de Vigo, estas investigaciones historiográficas sobre traductoras y escritoras foráneas omitidas por los discursos culturales androcéntricos han constituido un jalón importante en la recuperación de una genealogía traductora femenina en las culturas ibéricas.

Enmarcada en la historiografía feminista de la traducción, el artículo que presentamos a continuación quiere incorporar diferentes historia(s), en la línea de los nuevos enfoques postpositivistas y antiesencialitas de la historia de la traducción que no se basan en una conceptualización vertical y periodizada de la historia, sino en una de plural y descentrada, abierta a las interrelaciones entre las historias (véase, entre otros, Bandia 2006, Bastin y Bandia 2006, Munday 2014, Rundle 2014, Vidal 2018). Como ya avanzó Paul Bandia, el nuevo milenio ha revelado las limitaciones de las antiguas metodologías de la historiografía de la traducción y, por lo tanto, muchos autores han abogado por estudiar otras historias de la traducción olvidadas, (in)visibilizadas por los discursos dominantes, historias que tienen en cuenta

\footnotetext{
${ }^{1}$ Disponible en: <<http://bibliotraducion.uvigo.es $>>$ (Fecha consulta: 25.05.2019).
} 
“Transfer” XV: 1-2 (2020), pp. 115-141. ISSN: 1886-554

"issues of gender, ethics, postcolonialism, globalization, and minority in translation" (2006: 54).

En esta línea, este artículo suma tres historias subalternas, que no han sido atendidas por los discursos dominantes de la Historia en mayúsculas: la historia de la traducción, la historia de las mujeres y la historia de la edición. Así pues, nos proponemos estudiar la conexión entre "feminismo", "edición" y "traducción" durante el postfranquismo, a partir de dos colecciones de ensayo feminista, de autoras autóctonas y traducidas, de la editorial barcelonesa laSal, edicions de les dones (1978-1990): laSal Ensayo (1979-1989) y Cuadernos Inacabados (1981-1988).

\section{Notas sobre feminismos, franquismo y postfranquismo}

Durante las primeras décadas de la dictadura franquista la cultura oficial impuso los valores nacional-católicos y las mujeres se convirtieron en las protagonistas silenciadas de la historia cultural del Estado español. A partir de los sesenta, la simbólica apertura del segundo franquismo y el auge del feminismo de la segunda ola en otros países occidentales, tales como Estados Unidos, Francia, Italia y Gran Bretaña, propiciaron el interés editorial hacia los ensayos sobre cuestiones de la mujer. En este sentido, diversas publicaciones nacionales pusieron en evidencia que el feminismo empezaba a revivir y a organizarse. Entre otros trabajos, destacamos La mujer como mito y como ser humano (1961) y La mujer en España. Cien años de su historia (1860-1960) (1963), de María Laffitte; Los derechos laborales de la mujer (1965) y Mujer y sociedad (1969), de Lidia Falcón; Feminismo y espiritualidad (1964), de Lilí Álvarez; La dona a Catalunya (1966) y El feminismo ibérico (1970), de Maria Aurèlia Capmany, o La mujer en España (1967), de Mireia Bofill, Maria Lluïsa Fabra, Anna Sallés y Elisa Vallès. A grandes rasgos, estas primeras publicaciones ejemplifican los dos principales movimientos ideológicos que hicieron renacer y repensar el debate feminista después de la guerra: el catolicismo pro- 
“Transfer” XV: 1-2 (2020), pp. 115-141. ISSN: 1886-554

gresista, más o menos ligado al régimen, y los movimientos antifranquistas asociados a partidos de izquierdas clandestinos (véase, entre otros, Larumbe 2002, Nielfa 2003, Amorós 2009, Ferré Baldrich 2018).

Con la necesidad de beber de madres y hermanas simbólicas extranjeras inspiradoras, el ensayo feminista traducido ocupó un lugar preferencial en los debates asociacionistas y académicos del momento. Si durante la vigencia de la Ley de Prensa de 1938 las traducciones de obras feministas fueron totalmente prohibidas, a mediados de los sesenta, con la supuesta "liberalización" de la censura, que se materializó con la entrada en vigor de la Ley de Prensa e Imprenta de 1966, la llamada Ley Fraga, se publicaron dos obras fundacionales extranjeras del feminismo moderno: Le deuxième sexe (1949), de Simone de Beauvoir, y The feminine mystique (1963), de Betty Friedan. The feminine mystique se tradujo al castellano y al catalán en 1965 (Godayol 2014), y, Le deuxième sexe, al catalán, en 1968 (Godayol 2013, 2015, 2016a).

A partir de los setenta, en plena efervescencia de los feminismos internacionales y nacionales, aparecieron numerosos ensayos autóctonos, como El feminismo ibérico (1970), De profesión: mujer (1971), Carta abierta al macho ibérico (1973), El feminisme a Catalunya (1973), de Maria Aurèlia Capmany; Cartas a una idiota española (1974), de Lidia Falcón; Mujercitas (1975), de Núria Pompeia; Qué es el feminismo (1976), de Magda Oranich; Mujeres en lucha. El movimiento feminista en España (1977), de Amparo Moreno, o Cuaderno feminista: introducción al self-help (1978), de Leonor Taboada. Asimismo, con la complicidad de los grupos y asociaciones feministas y de algunos intelectuales y

\footnotetext{
${ }^{2}$ La versión castellana de Friedan incluyó un prólogo de la escritora católica Lilí Álvarez y, la versión catalana de Beauvoir, uno de la escritora progresista Maria Aurèlia Capmany. Cabe destacar que la traducción argentina de El segundo sexo (1954) circuló clandestinamente en España, dado que el aparato censor prohibió su importación en 1955. No existió una versión de la obra de Beauvoir hasta 1998, en la colección "Feminismos" de Cátedra.
} 
“Transfer” XV: 1-2 (2020), pp. 115-141. ISSN: 1886-554

editores de izquierdas, se empezaron a publicar títulos de autoras extranjeras de diferentes escuelas feministas (Godayol 2016b, 2018; Larraz 2018). Se incluyeron en colecciones de ensayo de editoriales progresistas que querían importar literatura prohibida hasta entonces: por ejemplo, en Barcelona, Anagrama publicó La liberación de la mujer: la larga lucha (1975) y Psicoanálisis y feminismo (1976), de Juliet Mitchell; Kairós, La dialéctica del sexo (1976), de Shulamith Firestone, o Fontamara, Unión obrera (1977), de Flora Tristán.

Con la muerte de Franco, en 1975, los colectivos feministas, hasta entonces muy localizados, empezaron a hacer redes y a trabajar incansablemente. A pesar de separarse más adelante, de entrada las diferencias ideológicas entre los diversos feminismos, liberales o marxistas, reformistas o radicales, no frustraron los intercambios y las actividades conjuntas a favor de los derechos de las mujeres. Del 6 al 9 de diciembre de 1975 se celebraron en Madrid las primeras Jornadas Nacionales para la Liberación de la Mujer y, del 27 al 30 de mayo de 1976, en Barcelona, las primeras Jornades Catalanes de la Dona, las más masivas de su tiempo (véase, entre otros, Balletbò 2004, Nash 2007, Llinàs 2008, Ferré Baldrich 2018). Estos encuentros se convirtieron en puntos de partida de grandes proyectos participativos: asociaciones, coordinadoras, jornadas, debates y charlas (véase Moreno 1977).

En Cataluña, en enero de 1977 empezó a funcionar la Coordinadora Feminista de Barcelona, plataforma autónoma e independiente de partidos y hombres, que integró diferentes grupos feministas, con diversidad de planteamientos y perspectivas. Entre otros, cabe destacar ANCHE (Associació Nacional de Comunicació Humana i Ecologia), Associació Catalana de la Dona, Colectivo Feminista de Barcelona, DOAN (Dones Antimilitaristes) o DAIA (Dones per a l'Autoconeixement i l'Anticoncepció) (véase, entre otros, Nash 2007; Ferré Baldrich 2018). En el marco de estos colectivos afloraron las revistas Dones en Lluita (1977-1983) y Vindicación Feminista (1976-1979), publicaciones de referencia del debate teórico feminista de la época (Larumbe 2002; Llinàs 2008). 
“Transfer” XV: 1-2 (2020), pp. 115-141. ISSN: 1886-554

Con el objetivo de compartir actividades entre los distintos grupos (radicales, subordinados a organizaciones políticas de izquierdas, terceras vías, etc.) y apelar a la diversidad e interdisciplinariedad de los feminismos, en 1977 nacieron algunos espacios físicosintelectuales feministas. En Barcelona, por ejemplo, destacaron La Llibreria de les Dones (1977-1982), el bar-biblioteca feminista laSal (1977-1980) y La Casa de la Dona o Casal (1979-1981) (Llinàs 2008, Godayol 2017).

Al final de los setenta llegó una "crisis", un punto de inflexión, con una polarización de debates, rupturas y escisiones. La aprobación de la Constitución, en 1978, y la celebración de las elecciones legislativas, en 1977 y en 1979, propició cambios y desencantos en el marco del movimiento feminista. La democracia parlamentaria abrió las puertas a la participación política de las mujeres en las instituciones; algunas, desde partidos como el PSC o el PSUC, se involucraron para aplicar los principios de igualdad que propugnaba el feminismo socialista, que integraba las defensoras de la doble militancia. Por otra parte, el feminismo independiente cobijó diversas sensibilidades (como reformistas, radicales, ex-miembros de partidos políticos, etc.), que defendían la militancia única al movimiento y eran contrarias a las estructuras jerárquicas patriarcales. A partir de 1982, paralelamente a la victoria del PSOE, se añadieron dos elementos nuevos en el escenario de los movimientos de mujeres, según la historiadora Elena Grau Biosca (2000: 745): por un lado, se instaló un "feminismo difuso", porque parte de la población ya había asumido algunas ideas y actitudes abogadas por el feminismo; por el otro, el feminismo estaba presente por primera vez en las instituciones. En 1983, se fundó el Instituto de la Mujer y, en 1987, el Institut Català de les Dones. Asimismo, a finales de los ochenta en las universidades se formaron grupos de investigación que empezaron a publicar sobre estudios de las mujeres y de género. 
“Transfer” XV: 1-2 (2020), pp. 115-141. ISSN: 1886-554

\section{laSal, edicions de les dones: primera editorial feminista del Estado}

El bar-biblioteca feminista laSal se inauguró el 6 de julio de 1977 en el barrio del Raval de Barcelona. En copropiedad y autogestionado por cinco activistas (María José Quevedo, Sat Sabater, Montse Solà, Carme Cases y Mari Chordà), que compraron el local con préstamos bancarios individuales, fue un bar en el que se organizaban actividades diversas, como exposiciones, seminarios de índole variada y presentaciones de libros, así como un centro de información que asesoraba a las mujeres jurídicamente, laboralmente y sanitariamente. laSal se convirtió en una "aula magna del feminismo", para decirlo como Maite Goicoechea (1978: 13), un espacio de libertad e intercambio de ideas entre diferentes feminismos. Todo un referente.

Un año después de abrir el bar-biblioteca laSal, nacía el sello editorial laSal, edicions de les dones, que se ubicaba enfrente. Vinculadas muchas al anterior proyecto, las fundadoras (Mari Chordà, Mariló Fernández, Isabel Martínez e Isabel Monteagudo) de entrada contactaron con otras editoriales, que solamente les ofrecieron secciones o apartados feministas. Movidas por una visión más ambiciosa de proyecto cultural, al estilo de las primeras editoriales feministas norteamericanas, finalmente decidieron instituir una empresa propia, laSal, edicions de les dones (véase Cases 1998; Plaza 1998; Llinàs 1998, 2008; Gustà 2009; Almerini 2014; Bofill 2014; Centre de Documentació de Ca la Dona 2014: 147; Godayol 2017). ${ }^{3}$ Tenía una doble voluntad: "dar a conocer las nuevas reflexiones y vivencias que estábamos explorando las mujeres" y "crear un espacio donde éstas pudieran ser compartidas, más allá de las tertulias y seminarios, que se organizaban en el bar-biblioteca laSal", asevera Mireia Bofill (2014: 47), una de sus máximas colaboradoras.

\footnotetext{
${ }^{3}$ En "Hacia un canon literario igualitario postfranquista: laSal, primera editorial feminista” (2017), Pilar Godayol realizó un estudio panorámico de la editorial e incluyó su catálogo completo.
} 
“Transfer” XV: 1-2 (2020), pp. 115-141. ISSN: 1886-554

El catálogo de laSal revela que se plantearon dos objetivos preferentes: por un lado, hacer visibles discursos y tendencias de la cultura feminista del momento a nivel nacional e internacional, y, por el otro, recuperar madres verticales y horizontales de todos los tiempos. Durante trece años vieron la luz más de sesenta títulos y se distribuyeron más de 180.000 ejemplares, sin contar las 135.000 agendas de la mujer. ${ }^{4}$ La editorial publicó, con cierta regularidad, en catalán y castellano. Se desarrollaron seis colecciones: una de narrativa (1978-1989), otra de poesía (1978-1981) y otra de ensayo (1979-1989), los Cuadernos Inacabados (19811988), los Manuales de Salud (1981-1989) y la colección Clàssiques Catalanes (1983-1989).

En 1978 se inauguraron dos colecciones: laSal Poesía y laSal Narrativa. Por una parte, laSal Poesía contó con seis poemarios de Mari Chordà, Rosa Fabregat, Carmen Ruiz, Marta Pessarrodona y Montserrat Abelló. Por la otra, laSal Narrativa integró dieciséis volúmenes: diez originales de autoras contemporáneas y seis traducciones de autoras clásicas y contemporáneas de diferentes geografías. La mayoría de traducciones fueron simbólicamente significativas para los colectivos feministas de la época: La bolchevique enamorada (1978), de Alejandra Kolontai, en la versión de Vasilisa Malyguina, publicada en 1928 por la Editorial Oriente; La Celina (1980), de Christiane Rochefort, en traducción de Mari Chordà; El paper de paret groc (1982), de Charlotte Perkins Gilman, que llegaba por primera vez a España en versión catalana de la poeta y traductora Montserrat Abelló; Mudas de piel (1982), de Verena Stefan, en traducción de Mireia Bofill; El país de ellas: una utopía feminista (1987), también de Gilman, en versión

\footnotetext{
${ }^{4}$ La Agenda de 1978 fue la primera publicación de laSal, edicions de les dones. Bajo la coordinación de Mari Chordà, era un pequeño cuaderno de notas con fotografías, citas y textos políticos, que consiguió un éxito impensable. Un año después se editaba también en castellano. El tiraje de la última edición, de 1990, fue de 24.000 ejemplares.
} 
“Transfer” XV: 1-2 (2020), pp. 115-141. ISSN: 1886-554

de la escritora Helena Valentí, y, finalmente, El armario (1988), de Rose Tremain, a cargo de Mireia Bofill.

Las dos siguientes colecciones de laSal, edicions de les dones se consagraron al ensayo feminista. En 1979 se abrió laSal Ensayo, una colección dedicada a temas actuales, que finalmente integró nueve títulos. Y, en 1981, se inauguró Cuadernos Inacabados, bajo la dirección de Mireia Bofill. De ambas colecciones hablaremos más adelante.

Además de Cuadernos Inacabados, en 1981 nacía otra colección: Manuales de Salud. Con la voluntad de informar a las mujeres sobre su cuerpo y salud, integró cinco volúmenes, de los cuales los tres primeros fueron traducciones: Masturbación (1981), de Jane Wallace, en versión de Maria Rosa Bernstein; Manual de la salud de la mujer: introducción al self-help (1983), de Nancy McKeith et al., en traducción de Ester Donato; y ¿Por qué sufrir? La regla y sus problemas (1983), de Lynda Birke y Katy Gardner, en una traducción colectiva de DAIA, Grup de dones.

En 1983, aparecía la última colección, la mítica Clàssiques Catalanes, bajo la dirección de Isabel Segura. En sus últimos tiempos, laSal pasó de divulgar las novedades de las autoras feministas europeas de la época a recuperar las escritoras clásicas de la cultura catalana. Con gran éxito, publicó desde obras antiguas de Duoda, Sor Isabel de Villena o Estefania de Requesens hasta contemporáneas de Clementina Arderiu, Aurora Bertrana, Víctor Català, Carme Montoriol, Dolors Montserdà, Anna Murià, Mercè Rodoreda y Maria Teresa Vernet. La colección incluye dos traducciones: Les Trobairitz. Poetes occitanes del segle XII (1983), versionadas por Alfred Badia e introducidas por Magda Bogin, y De mare a fill. Escrits d'una dona del IX (1989), de Duoda, traducidos y prologados por Mercè Otero. 
“Transfer” XV: 1-2 (2020), pp. 115-141. ISSN: 1886-554

\section{Las colecciones laSal Ensayo y Cuadernos Inacabados}

A finales de los años setenta y principios de los ochenta laSal, edicions de les dones abrió dos colecciones de ensayo feminista: laSal Ensayo (1979-1989) y Cuadernos Inacabados (1981-1988). Nacida un año después de la editorial, la colección laSal Ensayo se dedicó a temas contemporáneos relevantes, como la sexualidad, la prostitución, la pornografía, el pacifismo, el sexismo en los libros escolares, las terapias de grupo, la lucha por el voto de las mujeres en España o la presencia de las mujeres en la Revolución Francesa. Además de obras de autoras autóctonas como la clásica Clara Campoamor o las contemporáneas Martha Moia y Magda Catalá, se editaron cinco traducciones: La pequeña diferencia y sus grandes consecuencias (1979), de la periodista y pionera del movimiento feminista alemán Alice Schwarzer, en versión de M. Lizárraga; Antes muertas. Mujeres contra el peligro nuclear (1984), coordinado por Dorothy Thompson y traducido por Mireia Bofill, con bibliografía básica en castellano y catalán, así como direcciones útiles del Estado español; Esclavitud sexual de la mujer (1987), de la socióloga feminista norteamericana Kathleen Barry, en traducción de Paloma Villegas y Mireia Bofill; Fuera moldes: hacia una superación del sexismo en los libros infantiles y escolares (1987), del sociólogo francés Andrée Michel, en versión de María José Aubet y Mireia Bofill; 1789-1793, la voz de las mujeres en la revolución francesa: cuadernos de quejas y otros textos (1989), de varias autoras y en traducción de Antònia Pallach y con prólogo de Paule-Marie Duhet.

Solamente la última traducción, publicada en conmemoración del bicentenario de la Revolución Francesa, cuenta con una elaborada introducción (de veinticuatro páginas) de las activistas feministas nacionales Isabel Alonso y Mila Belinchón, que pone énfasis en la necesidad de rescatar y difundir textos escritos por mujeres de todos los tiempos con el objetivo de "recuperar la parte femenina de la Historia" (1989: vii). Asimismo, las prologuistas reclaman la visibilización de más fuentes primarias de la 
“Transfer” XV: 1-2 (2020), pp. 115-141. ISSN: 1886-554

microhistoria en femenino: "la publicación de fuentes históricas ligadas al pasado femenino está comenzando a ser relativamente frecuente y esperamos que esto sea sólo el inicio de un proceso que nos acercará de forma directa a las quejas, las esperanzas y las voces de las mujeres de otras épocas" (1989: vii). Cuando se refieren a los textos compendiados, cronológicamente comprendidos entre 1789 y 1793, resaltan su diversidad: "Algunos pueden sorprender por su ingenuidad, mientras que otros lo harán por la radicalidad de sus planteamientos o por su agudeza de análisis" (1989: vii). Finalmente, en la línea de historiadoras feministas como Joan Scott (1996) o Cristina Borderías (2009), Alonso y Belinchón cierran la introducción con unas palabras dedicadas a los cambios que ha motivado el feminismo de los setenta y los ochenta en la manera de enfocar la historia de las mujeres: "La renovación de la historiografía, propiciada fundamentalmente por investigadoras influenciadas por el feminismo, ha iniciado la reivindicación del pasado y de la experiencia histórica de las mujeres como objeto de investigación. Para ello ha sido necesario construir un nuevo marco conceptual y metodológico apropiado para dicho estudio" (1989: xxx-xxxi).

De las cinco traducciones de laSal Ensayo, tres son a cargo, en co-traducción, de Mireia Bofill, quien, a partir de 1981, dirigió la mítica colección Cuadernos Inacabados (1981-1988), que, con el cierre de laSal, edicions de les dones, a principios de los noventa pasaría a formar parte del catálogo de la editorial madrileña, acabada de crear, horas y HORAS.

Nacida en Chile en 1944, hija de exiliados, Mireia Bofill Abelló es una activista feminista barcelonesa que, desde finales de los años sesenta hasta nuestros días, ha participado en múltiples proyectos culturales y sociales relacionados con el movimiento de mujeres. Explica Bofill que su madre, la poeta y traductora Montserrat Abelló (1918-2014), fue su "primera influencia" (2014: 17). Madre e hija coincidieron en múltiples espacios feministas y, entre otras prácticas compartidas, tradujeron, a cuatro manos, Cartas a la madre (2000), de Sylvia Plath. En 1967 Bofill fue coautora del 
“Transfer” XV: 1-2 (2020), pp. 115-141. ISSN: 1886-554

libro pionero La mujer en España, que contaba con los siguientes capítulos: "La mujer en la sociedad", de Mireia Bofill, "La virtud", de Maria Lluïsa Fabra, "La mujer española y el pecado", de Anna Sallés y "Situación jurídica de la mujer en España", de Elisa Vallès; se acompañó con material fotográfico de Pilar Villarrazo. Más tarde, colaboró en los Grupos de Autoconciencia Feminista (GAF) barceloneses de los setenta, así como en la preparación de las Jornades Catalanes de la Dona de 1976 y la revista Dones en Lluita, nacida en el seno de la Coordinadora Feminista. Después se uniría al proyecto de la laSal, donde trabajaría de traductora y editora de Cuadernos Inacabados, tarea que continuaría en horas y HORAS. Después de laSal vinieron más espacios femeninos barceloneses con quien participar: Duoda, Centre de Cultura de Dones Francesca Bonnemaison, Ca la Dona, etc. En resumen, la vida de Bofill ha girado siempre alrededor de espacios de relación en femenino.

Cuadernos Inacabados publicó ocho volúmenes, de extensión breve y temas variados: cinco de autoras autóctonas (Eli Bartra, María Jesús Izquierdo, Amparo Moreno, Victoria Sau y Carmen Sáez Buenaventura) y tres de feministas internacionales en auge en ese momento: Brujas, comadronas y enfermeras: historia de las sanadoras. Dolencias y trastornos: política sexual de la enfermedad (1981), de las ensayistas y activistas sociales estadounidenses Barbara Ehrenreich y Deirdre English, en versión de Mireia Bofill y Paola Lingua; Por un feminismo materialista: el enemigo principal y otros textos (1982), de la socióloga feminista francesa Christine Delphy, a cargo de Mireia Bofill, Ángela Cadenas y Eulàlia Petit, con dibujos de Núria Pompeia, y El cuerpo a cuerpo con la madre. El otro género de la naturaleza. Otro modo de sentir (1985), de Luce Irigaray, en traducción de Mireia Bofill y Anna Carvallo. Como se puede apreciar, todas las obras fueron cotraducidas con Bofill.

Cuadernos Inacabados se dio a conocer con la traducción Brujas, comadronas y enfermeras: historia de las sanadoras. Dolencias y trastornos: política sexual de la enfermedad (1981), estudio 
“Transfer” XV: 1-2 (2020), pp. 115-141. ISSN: 1886-554

dedicado a recuperar la historia de las sanadoras y las trabajadoras sanitarias de Occidente durante dos periodos diferentes: la persecución de las brujas en la Europa medieval y el nacimiento de la profesión médica masculina en los Estados Unidos en el siglo XIX. En la "Nota editorial" introductoria, Bofill explica el origen de la colección y la apuesta de la editorial por publicar textos teóricos de pequeña extensión "que fueran elementos de trabajo, de discusión y de reflexión en los grupos de mujeres o entre cada una y la palabra escrita, ya en sí misma espacio de discusión" (1981: 1). Añade que su experiencia en el movimiento de mujeres de esos años le evidenció la necesidad de dar respuesta a exigencias básicas inmediatas:

Es la realidad, la confrontación de experiencias, la que genera el discurso teórico, que no aparece en forma de "manuales básicos" incuestionables y cerrados, sino a manera de publicaciones que sólo quieren ser un instrumento más de trabajo y reflexión. (1981: 1)

En resumen, Cuadernos Inacabados se constituyó "fruto de la necesidad de empezar a confrontar de una manera abierta, dinámica, elástica, las ideas, estudios y experiencias de las mujeres de todo el mundo" (1981: 1). El nombre escogido también reforzaba la provisionalidad y la intertextualidad: "Los lanzamos a modo de piedra en el agua a fin de encontrar el eco de nuestras palabras en otros cuadernos y así generar una conversación, rica, viva y por siempre inacabada..." (1981: 1), asevera Bofill.

Después de la "Nota editorial", Brujas, comadronas y enfermeras incluye otro paratexto, "Reflexiones sobre una experiencia", de DAIA (Mujeres para el Autoconocimiento y la Anticoncepción). Cabe destacar que DAIA fue una asociación de referencia en la lucha para la salud de las mujeres. Surgido en 1974 en el marco de las actividades del Grupo Planning de la Asociación de Mujeres Universitarias de Barcelona, recogió y divulgó las nuevas ideas, llegadas de otros países, sobre el control de reproducción y la libre expresión de la sexualidad. Editó hojas informativas y organizó 
“Transfer” XV: 1-2 (2020), pp. 115-141. ISSN: 1886-554

charlas sobre sexualidad y reproducción en centros sociales, vocalías y asociaciones de mujeres. Inspirados en la propuesta revolucionaria de los GAF (Grupos de Autoconciencia Feminista y selfhelp), nacidos a finales de los sesenta en Estados Unidos, en el marco de grupos como The New York Radical Women (NYRW) (1967), The Chicago Women's Liberation Union (CWLU) (1967 ) y WITCH (Women's International Terrorist Conspiracy from Hell) (1968), DAIA apostaba por centros de Planificación Familiar, independientes de las instituciones, para promover mecanismos de solidaridad y de autoayuda entre las mujeres. En general, el objetivo principal de estas agrupaciones era rescatar el control de las mujeres sobre su cuerpo, teniendo en cuenta que, hasta entonces, lo había ejercido el patriarcado a través de leyes e instituciones médicas. DAIA tuvo una duración de doce años y desapareció cuando el PSOE llegó al poder (véase Llinàs 2008: 7074).

En "Reflexiones sobre una experiencia", DAIA denuncia "el papel que la medicina juega en la opresión de la mujer" (1981: 2) y defiende el análisis de las autoras sobre las dos formas distintas de exclusión y manipulación que viven las mujeres en contacto con la institución médica: "la primera como trabajadoras de la sanidad, relegadas hoy a papeles secundarios" y "la segunda como sujetos pasivos en los que la medicina, desde su aparición como institución, ha encontrado un verdadero filón dadas nuestras características fisiológicas" (1981: 2). Asimismo, considera "el poder de la medicina como un poder más de tipo patriarcal" y animan a las mujeres "a recuperar su cuerpo" y a "iniciar experiencias que cuestionen realmente el papel de los técnicos en medicina", como los grupos self-help, los partos naturales o nacimientos sin violencia, etc. (1981: 2). En definitiva, como las autoras de Brujas, comadronas y enfermeras, DAIA busca desenmascarar la "aparente objetividad y cientifismo" de la institución médica y anima a las mujeres a "escucharse", a "rehacer una imagen de cuerpo en armonía, sano y libre" (1981: 4). 
“Transfer” XV: 1-2 (2020), pp. 115-141. ISSN: 1886-554

La segunda traducción de Cuadernos Inacabados fue Por un feminismo materialista: el enemigo principal y otros textos (1982), de la feminista marxista francesa, de raíz materialista, Christine Delphy, de cuyas teorías bebió, en gran parte, el Colectivo Feminista de Barcelona, liderado por Lidia Falcón. En 1977 Delphy fundó, con Simone de Beauvoir y otras activistas, la primera revista feminista de carácter teórico en lengua francesa, Questions Féministes (posteriormente, a partir de 1981, Nouvelles Questions Féministes). Delphy considera a la mujer como una clase social y, por lo tanto, su propósito es llevar a cabo una revolución feminista que acabe con la opresión femenina. Con el fin de cambiar la sociedad capitalista y machista, no solo pretende modificar el modo de producción, sino también las relaciones sociales, la cultura y la ideología. En Por un feminismo materialista: el enemigo principal y otros textos, se recogen, por primera vez, todos los escritos teóricos de Delphy, hasta entonces dispersos en varias revistas feministas, científicas y político-culturales, donde denuncia e investiga las explicaciones "clásicas" sobre la opresión de la mujer, además de proponer una teoría feminista que examine el fundamento material de esta opresión.

La traducción de Mireia Bofill, Ángela Cadenas y Eulàlia Petit se acompañó con dibujos de la ilustradora, humorista gráfica y escritora barcelonesa Núria Pompeia (1931-2016), pseudónimo de Núria Vilaplana Buixons. Pompeia es considerada una de las pioneras del cómic feminista en el Estado español. Colaboradora en periódicos y revistas, como Charlie Hebdo, CLIJ, Cuadernos para el Diálogo, Cuadernos de Pedagogía, Diari de Barcelona, El Món, L'Hora, Triunfo y Vindicación Feminista, ilustró carteles de actividades feministas tan importantes como el de las Jornades Catalanes de la Dona, en mayo de 1976, y el de las Jornades 20 anys de Feminisme a Catalunya, en mayo de 1996.

La tercera y última traducción de la etapa de laSal de Cuadernos Inacabados fue El cuerpo a cuerpo con la madre. El otro género de la naturaleza. Otro modo de sentir (1985), de la psicoanalista y escritora Luce Irigaray, una de las madres funda- 
“Transfer” XV: 1-2 (2020), pp. 115-141. ISSN: 1886-554

cionales del feminismo de la diferencia. Después de Speculum: espéculo de la otra mujer (1978), su tesis doctoral, y Ese sexo que no es uno (1982), ambas versiones publicadas por la editorial madrileña Saltés, fue la tercera obra que llegaba al Estado español de la autora feminista francesa de origen belga. Con una breve biografía introductoria y la bibliografía de la autora, este cuaderno compendia tres textos: una conferencia presentada en el $5^{\circ}$ Coloquio quebequés sobre Las mujeres y la locura (Montreal, 30-31 de mayo 1980), una conversación con Françoise Clédat, Xavier Gauthier y Anne-Marie de Vilaine y una entrevista con M. F. Hans y G. Lapouge. Como apunta la introducción (no firmada, pero seguramente de Bofill), Luce Irigaray

prosigue en estos textos su tarea de reconstrucción de la existencia de otra sexualidad: la nuestra. Una sexualidad diferente, ni mejor ni peor que la del hombre, pero que en todo caso va más lejos que los modelos impuestos por la ideología dominante, basados en la violencia y la pornografía. (Irigaray 1985: 1)

Cuadernos Inacabados fue la penúltima colección que inició laSal, la última fue Clàssiques catalanes, coordinada por Isabel Segura, quien, una vez cerrada laSal, continuó la tarea en Edicions de l'Eixample. A finales de los noventa la dirección, que había trabajado intensamente con grandes dosis de pasión y altruismo, decidió poner fin a aquel proyecto literario de ensueño.

La última encomienda de laSal fue de magnitud transnacional: la coordinación de la IV Feria Internacional del Libro Feminista, celebrada en las Drassanes de Barcelona, del 19 al 23 de junio de 1990. Las anteriores ediciones se habían llevado a cabo en Londres, en 1984; en Oslo, en 1986; y en Montreal, en 1988. A petición de la dirección de laSal, hacía dos años que el Ayuntamiento de Barcelona había presentado oficialmente la candidatura de la ciudad como sede de la feria. A pesar de haber decidido parar el proyecto editorial, las responsables de laSal, en especial Mireia Bofill, se implicaron en la organización del acto, conjun- 
“Transfer” XV: 1-2 (2020), pp. 115-141. ISSN: 1886-554

tamente con otras instituciones (Ayuntamiento de Barcelona, Generalitat de Catalunya, Instituto de la Mujer, Diputació de Barcelona y Ministerio de Cultura).

En total, la IV Feria Internacional del Libro Feminista de Barcelona reunió 201 editoriales, 14 librerías, 31 revistas y cien autoras de 36 países. Se realizaron más de 150 intervenciones de escritoras, editoras, traductoras, críticas literarias, ilustradoras, diseñadoras o distribuidoras nacionales e internacionales. Como ejemplo, vale la pena destacar que, en la mesa dedicada al "Placer/ reto de la traducción", intervinieron la traductora barcelonesa Mireia Bofill, las alemanas Traude Büihrmann y Karen NölleFischer, la holandesa Rita Gircour y las canadienses Suzanne de Lotbinière-Harwood y Nicole Brossard, ambas activistas de la escuela feminista de finales de los años ochenta, que, como hemos visto en la introducción, fueron pioneras en subvertir con su escritura o (re)escritura el discurso dominante patriarcal (Aubet 1991). En resumen, la Feria de Barcelona fue un éxito incontestable, a partir del cual nacieron múltiples proyectos, como la librería Pròleg, de Barcelona, o la editorial horas y HORAS, de Madrid, que finalmente integraría en su catálogo la colección Cuadernos Inacabados, igualmente capitaneada por Mireia Bofill (véase Piñol 1989, 1990a, 1990b, 1990c; Grases 2007; Bofill 2014).

\section{Conclusiones: "Un espacio de trabajo en relación"}

En el artículo "Décadas de feminismo: historia de mi práctica de la relación", Mireia Bofill, una de las editoras y la más prolífica traductora de ensayo de laSal, analizaba su trayectoria feminista y recordaba que la editorial fue, ante todo, "un espacio de trabajo en relación" (Bofill 2014: 30): desde la selección de los libros, su realización material y distribución, la maquetación, el diseño de las portadas, las traducciones, las correcciones, los prólogos y las introducciones, hasta la relación con las autoras y las ilustradoras, las presentaciones en librerías y espacios culturales, el contacto 
“Transfer” XV: 1-2 (2020), pp. 115-141. ISSN: 1886-554

con las periodistas y la crítica, el vínculo con otras editoras feministas internacionales, etc.

Proyecto colectivo voluntarista y subversivo, laSal, edicions de les dones publicó durante doce años regularmente gracias a la entrega personal y profesional de un grupo de intelectuales feministas barcelonesas. Aunque fue la primera del Estado español, surgió como otras muchas plataformas editoriales feministas anglo-americanas y europeas, gestionadas en contextos asociacionistas o universitarios, que emergieron con la eclosión del militantismo de la segunda ola feminista de finales de los años sesenta y setenta. Entre otras, podríamos destacar, en Estados Unidos, Know, Seal Press, Feminist Press y Kitchen Table Women of Color Press; en Canadá, The Women's Press y Éditions du remue-ménage; en Gran Bretaña, Virago, Feminist Books, Onlywomen, The Women's Press y Pandora Press,; en Francia, Des Femmes; en Alemania, Frauenoffensive y Orlanda, y, en Austria, Weiner Frauenverlag (Butalia y Menon 1995: 1-14). Como laSal, todas compartieron dos objetivos capitales: por un lado, recuperar y revalorizar protagonistas femeninas del pasado, y; por el otro, vestir teóricamente los nuevos discursos feministas ascendientes.

En un contexto histórico, político y social postfranquista, coincidiendo con los movimientos feministas de los setenta, laSal se movió por la ilusión y el empeño de recuperar el tiempo perdido y normalizar el feminismo de nuestro país introduciendo o visibilizando nuevas corrientes, obras y autoras. Uno de sus máximos propósitos fue combatir la orfandad materna crónica que había impuesto la dictadura, construyendo un espacio teórico de discusión y de reflexión que diera respuesta a tantas preguntas silenciadas. En este sentido, la importación de madres teóricas simbólicas, como Christine Delphy, Barbara Ehrenreich, Deirdre English, Luce Irigaray o Alice Schwarzer, fue vital para confrontar otras ideas, experiencias y maneras de luchar contra el patriarcado.

Como otras editoriales feministas internacionales, desaparecidas o absorbidas en los noventa por los grandes sellos, cuando 
“Transfer” XV: 1-2 (2020), pp. 115-141. ISSN: 1886-554

el compromiso político y la generación de beneficios tomaron direcciones incompatibles, laSal, edicions de les dones finalizó la actividad a principios de 1990. El 10 de marzo la periodista Rosa María Piñol anunciaba con tristeza en La Vanguardia la liquidación del sello editorial: "Hace doce años se fundaba en Barcelona la editorial laSal, dedicada a publicar libros de y para mujeres" (1990a). Casi un cuarto de siglo después, Mireia Bofill lo recordaba con estas palabras:

El final de laSal fue difícil, como todas las separaciones, y muy doloroso, pues todas habíamos invertido mucho emocionalmente en el proyecto. También fue un aprendizaje que me hizo comprender que la relación nos enriquece y nos hace crecer, pero no puede cubrir todas nuestras necesidades ni hacer realidad todos nuestros deseos. Que requiere una distancia y que, cuando se acaba, es bueno celebrar lo mucho que nos ha dado y seguir cada una su camino. (Bofill 2014: 31)

\section{Referencias bibliográficas}

ALMERINI, Katia. (2014). "LaSal, bar-biblioteca feminista en Barcelona. Empoderamiento femenino y cultura visual". Boletín de Arte, 35: 83-100.

AMORÓS, Celia. (2009). "Debates ideológicos en el movimiento feminista durante la transición española". En: MARTÍNEZ TEN, Carmen; GUTIÉRREZ LÓPEZ, Purificación \& GONZÁLEZ RUIZ, Pilar. (eds.). El movimiento feminista en España en los años 70. Valencia: Cátedra-Universitat de València-Instituto de la Mujer, pp. 189-201.

AUBET, María José. (ed.) (1991). Debats. Debates. IV Fira Internacional del llibre Feminista. Barcelona: Ajuntament de Barcelona.

BANDIA, Paul. (2006). "The Impact of Postmodern Discourse on the History of Translation". En: BASTIN, George \& BANDIA, 
“Transfer” XV: 1-2 (2020), pp. 115-141. ISSN: 1886-554

Paul. (eds.). Charting the Future of Translation History. Ottawa: University of Ottawa Press, pp. 45-58.

BASTIN, George \& BANDIA, Paul. (eds.). (2006). Charting the Future of Translation History. Ottawa: University of Ottawa Press.

BALLETBÒ, Anna. (2004). Una mujer en la Transición. Confesiones en la trastienda. Barcelona: Flor del Viento.

BOFILL, Mireia. (1981). “Nota editorial”. En: EHRENREICH, Barbara \& ENGLISH, Deirdre. Brujas, comadronas y enfermeras: historia de las sanadoras. Dolencias y trastornos: política sexual de al enfermedad. Barcelona: laSal, edicions de les dones, 1.

BOFILL, Mireia. (2014). "Décadas de feminismo: historia de mi práctica de la relación". Duoda, 47: 16-47.

BORDERÍAS, Cristina. (ed.) (2009). La historia de las mujeres: perspectivas actuales. Barcelona: Icaria.

BUTALIA, Urvashi \& MENON, Ritu. (1995). Making a difference: Feminist Publishing in the South. Boston: Bellagio Publishing Network.

CAMUS, Carmen; GÓMEZ CASTRO, Cristina \& WILLIAMS CAMUS, Julia. (2017). Translation, Ideology and Gender. Cambridge: Cam-bridge Scholars Publishing.

CASTRO, Olga \& ERGUN, Emek. (2017). Feminist Translation Studies. Local and Transnational Perspectives. London: Routledge.

CASES, Carme. (1998). "El Bar laSal". En: BOFILL, Mireia. (coord.) 20 anys de feminisme a Catalunya. Barcelona: Associació de Dones per a la Celebració dels 20 anys de les Primeres Jornades Catalanes de la Dona, pp. 278-279.

CENTRE DE DOCUMENTACIÓ DE CA LA DONA (2014). Els llibres de laSal i les nostres lectures. 9 d'abril 2014. Dossier. Barcelona: Ca la Dona, pp. 1-47.

FERRÉ BALDRICH, Meritxell. (2018). El maig de les dones: El moviment feminista a Catalunya durant la Transició. Tarragona: Arola-Publicacions Universitat Rovira i Virgili. 
“Transfer” XV: 1-2 (2020), pp. 115-141. ISSN: 1886-554

GRASES I MULLERACHS, Àngels. (2007). "L'amor a un projecte i les seves conseqüències: 16 anys de la Llibreria Pròleg". Duoda. Estudis de la Diferència Sexual, 32: 81-88.

GODAYOL, Pilar (2000). Espais de frontera. Gènere i traducció. Vic: Eumo. [2002. Spazi di frontiera. Genere e traduzione. Translated by Annarita Taronna. Bari: Palomar]

---. (2013). "Censure, féminisme et traduction: Le Deuxième sexe de Simone de Beauvoir en catalan". Nouvelles Questions Féministes, 32(2): 74-89.

---. (2014). "Feminism and translation in the 1960s: the reception in Catalunya of Betty Friedan's The feminine mystique", Translation Studies, 7(3): 267-213.

---. (2015). "Simone de Beauvoir bajo la dictadura franquista: las traducciones al catalán”. Quaderns de Filologia. Estudis Literaris, 20: 17-34.

---. (2016a). Tres escriptores censurades. Simone de Beauvoir, Betty Friedan \& Mary McCarthy. Lleida, Punctum. [2017: Tres escritoras censuradas. Simone de Beauvoir, Betty Friedan y Mary McCarthy. Granada: Comares.

---. (2016b). "Josep Maria Castellet, editor de autoras feministas traducidas". Trans. Revista de Traductología, 20: 87-100.

---. (2017). "Hacia un canon literario igualitario postfranquista: laSal, primera editorial feminista". En: SANTAEMILIA, José. (ed.). Traducir para la igualdad sexual. Granada: Comares, pp. 49-62.

---. (2018). "Feminismo, traducción y censura en el posfranquismo: "La Educación Sentimental", de Anagrama". En: ZARAGOZA Gora; MARTÍNEZ SIERRA, Juan José; CEREZO MARCHÁN, Beatriz \& RICHART MARSET, Mabel. (eds.). Traducción, género y censura en la literatura y en los medios de comunicación. Granada: Comares, pp. 13-26.

GODAYOL, Pilar \& TARONNA, Annarita. (eds.). (2018). Foreign Women Authors under Fascism and Francoism: Gender, Translation and Censorship. Cambridge: Cambridge Scholars Publishing. 
“Transfer” XV: 1-2 (2020), pp. 115-141. ISSN: 1886-554

GOICOECHEA, Maite. (1978). "Nacida de mujer o la desmitificación del útero". Vindicación feminista, 24 (junio): 13.

GUSTÀ, Marina. (2009). "Els estudis de literatura d'autora a Catalunya". En: CASSANY, Enric. (ed.). Gènere i modernitat a la literatura catalana contemporània. Lleida: Punctum \& GELCC, pp. 39-50.

LARRAZ, Fernando. (2018). "Gender, translation, and censorship in Seix Barral's "Biblioteca Breve" and "Biblioteca Formentor" (1955-1975)". En: GODAYOL, Pilar \& TARONNA, Annarita. (eds.). Foreign Women Authors under Fascism and Francoism. Gender, translation and censorship. Cambridge: Cambridge Scholars Publishing, pp. 128-145.

LARUMBE, María Ángeles. (2002). Una inmensa minoría. Influencia y feminismo en la Transición. Zaragoza: Prensas Universitarias de Zaragoza.

LLINÀS, Concha. (1998). "Les publicacions de laSal, edicions de les dones". En: BOFILL, Mireia. (coord.). 20 anys de feminisme a Catalunya. Barcelona: Associació de Dones per a la Celebració dels 20 anys de les Primeres Jornades Catalanes de la Dona, pp. 382-385.

---. (2008). Feminismes de la Transició a Catalunya. Textos i materials. Barcelona: Horsori Editorial.

MUNDAY, Jeremy. (2014). Using sources to produce a microhistory of translation and translators: theoretical and methodological concerns. The Translator, 20(1): 64-80.

NASH, Mary. (2007). Dones en transició. De la resistència política a la legitimitat feminista: les dones en la Barcelona de la transició. Barcelona: Ajuntament de Barcelona.

NIELFA, Gloria. (ed.) (2003). Mujeres y hombres en la España franquista: sociedad, economía, política, cultura. Madrid: Instituto de Investigaciones Feministas-Editorial Complutense.

PIÑOL, Rosa M. (1989). "Apoyo institucional a la Feria del Libro Feminista del 90 en Barcelona". La Vanguardia (10 mayo): 39.

---.. (1990a). "Cierra laSal, única editorial feminista que existía en España”. La Vanguardia, Cultura (10 marzo): 36. 
“Transfer” XV: 1-2 (2020), pp. 115-141. ISSN: 1886-554

--.. (1990b). "La literatura feminista se cita en Barcelona". La Vanguardia (20 junio): 53.

--.. (1990c). "Nueve autoras de distintas culturas coinciden en asociar escritura y libertad". La Vanguardia (23 junio): 42.

PLAZA, Elsa. (1998). "laSal, Bar-Biblioteca Feminista: un espai per a la utopia". En: BOFILL, Mireia. (coord.) 20 anys de feminisme a Catalunya. Barcelona: Associació de Dones per a la Celebració dels 20 anys de les Primeres Jornades Catalanes de la Dona, pp. 280-283.

RUNDLE, Christopher. (2014). "Theories and methologies of translation history: the value of an interdisciplinary approach". The Translator, 20(1): 2-8.

SANTAEMILIA, José. (ed.) (2017). Traducir para la igualdad sexual / Translating for sexual equality. Granada: Comares.

SCOTT, Joan W. (1996): Feminism and history. Oxford: Oxford University Press.

VIDAL CLARAMONTE, María del Carmen África. (1998). El futuro de la traducción. València: Institució Alfons el Magnànim.

---. (2018). La traducción y la(s) historia(s). Granada: Comares.

ZARAGOZA, Gora; MARTÍNEZ SIERRA, Juan José; CEREZO, Beatriz \& RICHART, Mabel. (eds.) (2018). Traducción, género y censura en la literatura y en los medios de comunicación. Granada: Comares. 
“Transfer” XV: 1-2 (2020), pp. 115-141. ISSN: 1886-554

\section{APÉNDICE: EL ENSAYO FEMINISTA DE LASAL, EDICIONS DE LES DONES}

\section{laSal Ensayo (1978-1989)}

SCHWARZER, Alice. (1979). La pequeña diferencia y sus grandes consecuencias. Traducción de M. Lizárraga.

MOIA, Martha I. (1981). El no de las niñas. Feminario antropo-lógico.

CAMPOAMOR, Clara. (1981). El voto femenino y yo.

THOMPSON, Dorothy et al. (1984). Antes muertas. Mujeres contra el peligro nuclear. Traducción de Mireia Bofill.

BARRY, Kathleen. (1987). Esclavitud sexual de la mujer. Traducción de Paloma Villegas y Mireia Bofill.

MICHEL, Andrée. (1987). Fuera moldes: hacia una superación del sexismo en los libros infantiles y escolares. Traducción de María José Aubet y Mireia Bofill.

CATALÁ, Magda. (1988). El cuerpo de la psicología femenina.

OSBORNE, Raquel. (1989). Las mujeres en la encrucijada de la sexualidad: una aproximación desde el feminismo.

VV.AA. (1989). 1789-1793, la voz de las mujeres en la revolución francesa: cuadernos de quejas y otros textos. Traducción de Antònia Pallach i Estela.

\section{Cuadernos inacabados (1981-1988)}

EHRENREICH, Barbara \& ENGLISH, Deirdre. (1981). Brujas, comadronas y enfermeras: historia de las sanadoras. Dolencias y trastornos: política sexual de al enfermedad. Traducción de Mireia Bofill y Paola Lingua.

DELPHY, Christine. (1982). Por un feminismo materialista: el enemigo principal y otros textos Traducción de Mireia Bofill, Ángela Cadenas y Eulàlia Petit.

IZQUIERDO, María Jesús. (1983). Las, los, les (lis, lus): el sistema sexo-género y la mujer como sujeto de transformación social. 
“Transfer” XV: 1-2 (2020), pp. 115-141. ISSN: 1886-554

IRIGARAY, Luce. (1985). El Cuerpo a cuerpo con la madre. El otro género de la naturaleza. Otro modo de sentir Traducción de Mireia Bofill y Anna Carvallo.

MORENO, Amparo. (1986). El Arquetipo viril protagonista de la historia: ejercicios de lectura no androcéntrica.

SAU, Victoria. (1986). Aportaciones para una lógica del feminismo.

BARTRA, Eli. (1987). Mujer, ideología y arte: ideología y política en Frida Kahlo y Diego Rivera.

SÁEZ BUENAVENTURA, Carmen. (1988). Sobre mujer y salud mental.

Fecha de recepción: 2.05.2019 Fecha de aceptación: 01.06.2019

\section{Resumen:}

Después de la muerte de Francisco Franco, en pleno auge de los movimientos sociales y culturales de la mujer, emergieron editoriales y colecciones feministas. En Barcelona, en 1977 nacía el espacio híbrido y polivalente, entre cultural y político, café-bar laSal y, un año más tarde, se fundaba la primera editorial feminista del Estado, laSal, edicions de les dones (1978-1990).

En este artículo, después de contextualizar los feminismos de los años setenta y ochenta y resumir brevemente el catálogo de laSal, edicions de les dones, así como destacar su modo de trabajar "en relación", estudiaremos las dos colecciones que la editorial dedicó al ensayo feminista: laSal Ensayo (1978-1989) y Cuadernos Inacabados (1981-1988). Ambos proyectos incorporaron textos de autoras autóctonas y foráneas. Comprobaremos que, con el objetivo de luchar contra la orfandad materna crónica que había impuesto el franquismo, la importación de literatura feminista extranjera fue clave para restaurar la memoria histórica de las mujeres y crear debate sobre su identidad. 
“Transfer” XV: 1-2 (2020), pp. 115-141. ISSN: 1886-554

Palabras clave: Género y traducción, Feminismo y traducción, Historiografía feminista de la traducción, Historia de la edición feminista.

\title{
"A WORKSPACE FOR INTERRELATING": FEMINIST ESSAYS TRANSLATED BY LASAL, EDICIONS DE LES DONES
}

\begin{abstract}
:
After the death of Francisco Franco, in the midst of the appearance of women's social and cultural movements, feminist publishing houses and collections emerged. In Barcelona, the hybrid, cultural-cum-political cafe-bar laSal was born in 1977, and, a year later, the first feminist publishing house in Spain, laSal, edicions de les dones (1978-1990), was founded.

In this article, after contextualising feminisms during the Spanish transition to democracy, and briefly summarizing the catalog of laSal, edicions de les dones, as well as examining their way of working "interrelating", we will study the two series that were devoted to feminist essays: laSal Ensayo (1978-1989) and Cuadernos Inacabados (1981-1988). Both projects incorporated texts by autochthonous and foreign authors. We will verify that, in order to fight against the chronic maternal orphanhood that Francoism had imposed, the importation of foreign feminist literature was key to restoring the historical memory of women and generating debate about their identity.
\end{abstract}

Keywords: Gender and Translation, Feminism and Translation, Feminist Historiography of Translation, History of Feminist Publishing. 